\title{
Demographic and Clinical Factors Associated with Development of Type 2 Diabetes: A Review of the Literature
}

This article was published in the following Dove Press journal: International Journal of General Medicine

\author{
Yacob Pinchevsky (D) \\ Neil Butkow' \\ Frederick J Raal $\mathbb{D}^{2}$ \\ Tobias Chirwa $\mathbb{D}^{3}$ \\ Alan Rothberg ${ }^{4}$ \\ 'Department of Pharmacy and \\ Pharmacology, School of Therapeutic \\ Sciences, Faculty of Health Sciences, \\ University of the Witwatersrand, \\ Johannesburg, South Africa; \\ ${ }^{2}$ Carbohydrate and Lipid Metabolism \\ Research Unit, Faculty of Health \\ Sciences, University of the \\ Witwatersrand, Johannesburg, South \\ Africa; ${ }^{3}$ Division of Epidemiology and \\ Biostatistics, School of Public Health, \\ Faculty of Health Sciences, University of \\ the Witwatersrand, Johannesburg, South \\ Africa; ${ }^{4}$ School of Therapeutic Sciences, \\ Faculty of Health Sciences, University of \\ the Witwatersrand, Johannesburg, South \\ Africa
}

\begin{abstract}
Diabetes mellitus is a complex and chronic condition that requires lifelong management and interaction with a healthcare system. Failure to control risk factors through preventive care may lead to a host of diabetes-related complications. Underperforming health care systems and poor awareness among the general population/healthcare professionals has been suggested as reasons why so many patients remain undiagnosed. Due to the asymptomatic nature of early and even intermediate diabetes mellitus, several years may pass without any diagnosis before complications begin to manifest. Other factors include age, gender, ethnicity, education, marital and unemployment status which may also increase the risk of developing morbidity and mortality associated with diabetes mellitus. This review summarizes the current demographic risk factors and clinical characteristics associated with diabetes mellitus. A literature search was conducted using PubMed, MEDLINE, and Sabinet by using the following search terms: diabetes mellitus, risk factors, characteristics and complications.
\end{abstract}

Keywords: diabetes mellitus, risk factors, characteristics, complications

\section{Background}

The number and prevalence of people with diabetes mellitus (DM) are rapidly rising. Diabetes is a chronic progressive condition that results in significant morbidity, premature death and economic burden to any healthcare system. Globally, as many as 5.0 million people aged between 20 and 99 years perished from diabetesrelated mortality in $2017 .{ }^{1}$ This makes DM more lethal than the combined number of deaths from HIV/AIDS (1.5 million), tuberculosis (1.5 million), and malaria (0.6 million), with almost half (46.6\%) of the deaths aged $<60$ years. ${ }^{2}$ According to the International Diabetes Federation (IDF), globally, there were 463 million people or $9.3 \%$ of the world's population living with diabetes in 2019 , with $80 \%$ originating from low- and middle-income countries (LMICs). ${ }^{1}$ Overall, it is estimated that 700 million or $10.9 \%$ of the world's population will have the disease by 2045 (Table 1). ${ }^{1}$

Diabetes mellitus is a disorder characterised by glycaemic disturbances as a result of defects in insulin secretion, insulin action or both. ${ }^{3}$ Poor insulin action leads to abnormalities of carbohydrate, fat and protein metabolism in target tissues. ${ }^{4}$ Approximately $5-10 \%$ of patients with diabetes have type 1 diabetes mellitus (T1DM) which occurs through the destruction of pancreatic beta-cells. ${ }^{5}$ Patients
Correspondence: Yacob Pinchevsky 7 York Road, Parktown, Johannesburg 2193, South Africa

Tel +27828374082

Fax +27 II 0264700

Email jpinchevsky@gmail.com 
Table I Estimated Total Number of Adults (20-79 Years) with Diabetes Mellitus in 2019, 2030 and 2045

\begin{tabular}{|c|c|c|c|}
\hline & 2019 & 2030 & 2045 \\
\hline \multicolumn{4}{|l|}{ Total Population } \\
\hline $\begin{array}{l}\text { Total world } \\
\text { population } \\
\text { Adult population } \\
\text { (20-79 years) }\end{array}$ & $\begin{array}{l}7.7 \text { billion } \\
\text { 5. } 0 \text { billion }\end{array}$ & $\begin{array}{l}8.6 \text { billion } \\
5.7 \text { billion }\end{array}$ & $\begin{array}{l}9.5 \text { billion } \\
6.4 \text { billion }\end{array}$ \\
\hline \multicolumn{4}{|c|}{ Diabetes Population (20-79 years) } \\
\hline Global prevalence & $9.3 \%$ & $10.2 \%$ & $10.9 \%$ \\
\hline $\begin{array}{l}\text { Number of people } \\
\text { with diabetes }\end{array}$ & 463.0 million & 578.4 million & 700.2 million \\
\hline $\begin{array}{l}\text { Number of deaths } \\
\text { due to diabetes }\end{array}$ & 4.2 million & - & - \\
\hline $\begin{array}{l}\text { Total health } \\
\text { expenditures for } \\
\text { diabetes* }\end{array}$ & $\begin{array}{l}\text { USD } \\
760.3 \text { billion }\end{array}$ & $\begin{array}{l}\text { USD } \\
824.7 \text { billion }\end{array}$ & $\begin{array}{l}\text { USD } \\
845.0 \text { billion }\end{array}$ \\
\hline
\end{tabular}

Notes: *Health expenditures for people with diabetes are assumed to be on average two-fold higher than people without diabetes. Adapted with permission from International Diabetes Federation. IDF Diabetes Atlas. 9th ed. Brussels, Belgium: International Diabetes Federation; 2019. (C) 2019 International Diabetes Federation.'

with T1DM are typically younger and absolutely insulin deficient, and therefore require exogenous insulin. ${ }^{6}$ Many patients with T1DM are highly susceptible to diabetic ketoacidosis (DKA), diabetic coma and/or even death. ${ }^{7}$ Aetiology has been postulated to be immune-mediated. ${ }^{8}$ Latent Autoimmune Diabetes in Adults (LADA) is, as the name suggests, T1DM which occurs later in life. ${ }^{8}$

The majority of patients with DM (90-95\%) develop type 2 diabetes mellitus (T2DM). ${ }^{5}$ This type of DM arises through the gradual loss of insulin secretion which may be partly related to obesity, pancreatic beta-cell function decline and eventual hyperglycaemia. ${ }^{9}$ Patients with T2DM develop insulin resistance, which ranges from a relative deficiency to a complete insulin secretory defect. $^{5}$ The aetiology of T2DM is most likely associated with the interaction between genes and the environment. ${ }^{10}$ A study by Pierce et $\mathrm{al}^{11}$ demonstrated that a family history of T2DM increases the chances of developing this disease $2-4$ fold. Similarly, there is a $40 \%$ lifetime risk of developing T2DM when at least one parent has the condition. ${ }^{12}$ When both parents have T2DM the risk is increased to $70 \%$. Environmental or epigenetic causes of T2DM are evident in the absence of concordance in monozygotic twins. ${ }^{13}$ The pathogenesis of DM may be influenced by dysbiosis of the intestinal microbiota whereby specific pathogens or metabolites produced by gut bacteria have detrimental effects on metabolic pathways. ${ }^{14}$ Type 2 diabetes mellitus is considered a "disease of lifestyle", hence frequently found in individuals with raised Body Mass Index (BMI), blood pressure and other cardiovascular risk factors. Therefore, management of T2DM includes changes in the diet and exercise routine, various forms of pharmacotherapy including combinations of antihyperglycaemic agents (oral and often insulin), antihypertensives, lipid-lowering and sometimes anti-platelet therapy. ${ }^{3}$

\section{Diabesity}

Globally, more than 600 million people are clinically obese. $^{15,16}$ In the United States (US) alone, more than 1 in 3 adults and $17 \%$ of the youth were obese between 2011 and $2014 .{ }^{17}$ One study suggests that the obesity pandemic has gone as far as reaching two-thirds of adults living in the United States. ${ }^{18}$ Due to a worldwide increase in highcalorie diets, sedentary lifestyles and urbanization, obesity has now become an established risk factor for T2DM and/ or metabolic syndrome (MS). ${ }^{19}$ Hence, the obesity prevalence is being paralleled by similar increases in the number of patients with $\mathrm{T} 2 \mathrm{DM}$ or $\mathrm{MS}^{20}$ Often found in tandem in patients, raised BMI has been shown to be the strongest risk factor for the development of DM. Obesity is defined using cut points of BMI which measures the relationship between weight and height and is not age or gender dependent. ${ }^{21}$ On the other hand, total body fat varies by age, gender and ethnicity. $\mathrm{Hu}$ et $\mathrm{al}^{22}$ reported in an analyses of two cohorts that for every two extra years of a person being overweight there was a $9 \%$ increased risk of developing T2DM. In obese patients, the risk increased to $14 \%$ for patients exposed for the same duration. In addition to increased DM risk, obesity has been established as an independent risk factor for cardiovascular disease through its indirect influence on multiple comorbidities such as hyperlipidaemia, hypertension, insulin resistance, endothelial dysfunction and inflammation. ${ }^{23}$ Certain minority ethnic groups seem to be at a higher risk of developing obesity and DM, whilst children/adolescents share equal risk as their adult counterparts. ${ }^{24}$ In children it has been reported that as many as $41.3 \%$ spend more than $3 \mathrm{hrs}$ a day engaged in video games or watching television, which was independently associated with weight gain. ${ }^{25,26}$ Rising trends in abdominal obesity in children and adolescents between 1988-1994 and 1999-2004 were as high as $65.4 \%$ (from $10.5 \%$ to $17.4 \%$ ) for boys and $69.4 \%$ (from $10.5 \%$ to $17.8 \%$ ) for girls. ${ }^{27}$ In adolescents, T2DM arises from pathways that are similar to those proposed in 
adults. $^{28}$ These range from insulin resistance to failure of pancreatic $\alpha$-cells, $\beta$-cells, incretin production, kidney glucose filtration and lipolysis. ${ }^{27}$ Likewise, complications and comorbidities develop in a similar fashion in adolescents as with adults with T2DM. However, adolescents with T2DM present with a disease that rapidly progresses, has treatment challenges, and both micro- and macrovascular complications develop at a rapid pace. ${ }^{29}$ To treat hyperglycaemia in adolescents with T2DM, lifestyle modification together with biguanides (metformin) and/or insulin have been recommended. ${ }^{30}$ For those who require additional long-term glycaemic improvements and weight loss, early bariatric surgery has a place, although not yet established as a mainstream option due to limited data. ${ }^{31,32}$

\section{Undiagnosed Diabetes Mellitus}

As many as 175 million people are estimated to be undiagnosed and living with DM. ${ }^{33}$ This figure ranges from as many as $24.1 \%$ to $75.1 \%$ of all diabetes cases across different regions, with $83.8 \%$ originating from LMICs. ${ }^{32}$ The Pacific Island populations have been shown to have the highest prevalence of undiagnosed DM. ${ }^{32}$ Underperforming healthcare systems and poor awareness among the general population/healthcare professionals have been suggested as reasons why so many patients remain undiagnosed. Other reasons include few or even an absence of symptoms which are commonly associated with the condition. The initial protracted and asymptomatic period of T2DM may last several years before a diagnosis of T2DM is finally made, which directly contributes to complications that arise. ${ }^{3}$ The following symptoms are characteristic of DM: thirst, polyuria, polydipsia, blurred vision, unexplained weight loss and polyphagia. The most devastating clinical manifestations are diabetic ketoacidosis (DKA) and a non-ketotic hyperosmolar state, both of which in the absence of treatment, result in lethargy, stupor, diabetic coma and/or death. According to Motala, DM was detected in $36 \%$ fewer patients ( $2.5 \%$ vs $3.9 \%$ of the cohort) when only the fasting plasma glucose test was performed rather than an oral glucose tolerance test (OGTT). ${ }^{34}$ Hence, fewer patients with impaired glucose tolerance (pre-diabetes) would have been diagnosed. Plantinga et $\mathrm{al}^{35}$ showed that in the US as many as $41.7 \%$ of individuals with previously undiagnosed DM presented with chronic renal disease. In China, diabetic retinopathy was found to be $>30 \%$ among undiagnosed individuals with DM. ${ }^{36}$ With undiagnosed DM carrying a similar risk of mortality as diagnosed DM, and a 1.5 - to 3.0-fold increased risk of mortality compared to non-diabetic individuals, there is clearly a major need for higher-quality screening. ${ }^{37,38}$

Previous data have indicated that there are independent associations between age, age at diagnosis, diabetes duration and the risk of macrovascular events and/or death, whilst only diabetes duration is independently associated with the risk of microvascular complications. ${ }^{39}$ Macrovascular complications may arise across all age groups (albeit more commonly in older DM patients). Hence younger patients with DM are more likely to develop microvascular complications earlier. One study proved that the development of retinopathy in patients with T1DM will occur after continuous exposure to hyperglycaemia. ${ }^{40}$ However, the same study also showed the distinction between duration of exposure (at a certain threshold) and intensity of the hyperglycaemia, with the former risk factor having a greater effect on microvascular complications. Similarly, it has been demonstrated that retinopathy in patients with DM was more correlated with the duration of DM than with the age of onset of the disease. ${ }^{41}$ Therefore, earlier and more intensive control is needed in DM, particularly in overweight patients in order to minimize the risk of complications.

\section{Complications Associated with Diabetes Mellitus}

The T2DM condition is associated with a multitude of complications such as cardiovascular disease (CVD) and diabetic retinopathy, neuropathy and nephropathy. ${ }^{42}$ Rates of complications have been shown to be high in people with previously-undiagnosed DM compared to nondiabetic patients. As many as $25 \%$ of patients with T2DM present with retinopathy at diagnosis. Mbanya and Sobngwi ${ }^{43}$ showed that diabetic retinopathy complications are seen in $15-55 \%$ of DM patients, with a large percentage of these patients having proliferative retinopathy and/or macular oedema. Whilst $32-57 \%$ of DM patients develop renal complications (microalbuminuria or macroalbuminuria) within 5-10 years of their diabetes duration, half of the patients on maintenance haemodialysis also have a positive diagnosis for DM. ${ }^{42,44,45}$ In an article on the cardiovascular complications of DM in subSaharan Africa, the authors discuss the increasing prevalence of major and emerging cardiovascular risk factors and their role in the growing burden of cardiovascular disease. ${ }^{46}$ Diabetes in all its forms is one of the main 
cardiovascular risk factors. Close to $15 \%$ of patients with stroke have diabetes, approximately $30 \%$ of patients treated in cardiovascular intensive care units have diabetes, and 2 of every 3 diabetic patients will die as a result of cardiovascular complications. ${ }^{45}$ Overall, patients with T2DM have mortality rates approximately twice those without diabetes of equivalent age. Clinical trials targeting modifiable risk factors have shown efficacy and reduction in complications associated with DM, thus, many of the challenges associated with DM are modifiable and offer the potential for improvement. ${ }^{41}$

\section{Ethnicity/Culture}

Evidence suggests that lifestyle habits and health behaviours are directly linked to risk factors and prevalence of DM. $^{47}$ While classical risk factors such as raised blood pressure, dyslipidaemia, smoking and obesity contribute towards the development of DM, there are considerable disparities in the susceptibilities of certain ethnic groups. For example, in a group of 3193 men and 561 women aged 40-69 years studied in the United Kingdom (UK), in comparison with the Caucasians the Asian group not only had a higher prevalence of DM (19\% vs $4 \%$ ) but also higher blood pressures, higher fasting and postglucose serum insulin concentrations, higher plasma triglyceride, and lower HDL cholesterol concentrations. ${ }^{48}$ In the same study, mean waist-hip girth ratios and trunk skinfolds were higher in the Asian group. ${ }^{47}$ Similarly, angiography studies have shown that in comparison with Caucasians, Asians in the UK were more likely to have triple vessel disease, several lesions on angiography and non-discrete lesions. ${ }^{49}$ More worrying is the fact that Asians generally have smaller total coronary vessel diameters compared with Caucasians, which may increase technical difficulties and affect therapeutic coronary interventions. ${ }^{50}$ Statistical data from the US suggest that African American adults are at least 50\% more likely to have DM than their Caucasian counterparts. ${ }^{51}$ Whilst no clear reasons were provided, contributing factors such as modern lifestyle factors (which promote obesity), socioeconomic and direct genetic propensity or geneenvironmental interactions were all postulated. ${ }^{50}$ In a large, prospective cohort analysis of more than two million adult members of a Kaiser Permanente Northern California integrated healthcare delivery system, in which all participants had uniform access to healthcare, the DM prevalence and incidence rates in the combined Asian and Pacific Islanders group were greater than
Caucasians, but lower than Latinos or African Americans. ${ }^{52}$ Strikingly, the Pacific Islanders group had more than three times the incidence of DM relative to Caucasians, and a $75 \%$ increased DM incidence compared with African Americans and Latinos. ${ }^{51}$ If the analysis were to consider minority Asian subgroups, then the previous study's conclusions may have differed, given the fact that the larger subgroups (Chinese and Filipinos) most likely influenced the Asian group's overall standing. ${ }^{53}$ Consequently, treatment of diabetes should not only be multifactorial, but also tailored to the cultural backgrounds of the patient. Cooper-Patrick et $\mathrm{al}^{54}$ have shown that when patients and physicians share a similar ethnic background, better outcomes are observed. Hence, differences across ethnic diversities require different strategies in understanding and improving the health outcomes among distinct and perhaps higher-risk ethnic groups.

\section{The Aging Process}

As many as 10.9 million US adults aged $\geq 65$ years have been diagnosed with DM. ${ }^{55}$ The incidence rates tend to increase with age until approximately 65 years, after which both the incidence and prevalence rates seem to remain stable. ${ }^{54}$ Diabetes mellitus in older adults who are diagnosed after the age of 65 years is known as "incident DM", which differs from long-standing DM where onset occurs in middle age or earlier. ${ }^{56}$ The regular anatomical and physiological changes associated with the aging process are in fact hastened with DM, resulting in a reduction in life expectancy. ${ }^{57,58}$ In fact, it has been shown that adults aged 55 to 64 years who had DM experienced a life expectancy reduction of up to 8 years. ${ }^{59,60}$ The continued exposure to hyperglycemia induces oxidative stress, which further results in systematic endothelial dysfunction and vascular complications. Several molecular mechanisms have been proposed to explain the hyperglycemia-induced tissue damage found in patients with DM, one of which includes formation of advanced glycation end-products (AGEs) which are responsible for the pathogenesis of diabetic complications such as retinopathy, nephropathy, neuropathy and cardiomyopathy. ${ }^{61}$

\section{Gender Differences}

There is growing evidence that T2DM and its complications are related to gender differences. These differences occur as a result of hormonal variations, sociocultural behaviours, environmental changes (diet, lifestyle, stress, attitudes) and gene-environment interactions. ${ }^{62}$ For 
instance, men are more likely to be diagnosed with T2DM at an earlier age and with a lower BMI, whilst obesity, a strong risk factor of T2DM, is more commonly found in women upon diagnosis. ${ }^{63}$ Thus, females who attain a higher BMI tend to develop DM faster than men. Although women without DM generally have less risk of cardiovascular events than men, a change in glucose metabolism appears to reverse this phenomenon. ${ }^{64}$ This may be due to the fact that females have increased capacity for adipocyte enlargement which could lead to fat deposition abnormalities. ${ }^{65}$ Furthermore, endocrine changes caused by the onset of menopause in women, lowers oestrogen production, leading to changes such as an increase in proinflammatory abdominal adipose tissue. As a result, the oestrogen-derived cardioprotection normally active in women is lost over time, increasing the cardiovascular risk. ${ }^{66}$ In a pooled analysis of 900000 individuals across 64 cohorts and 28,000 coronary events, DM accounted for a three-fold increase in the risk of incident heart disease in women, whereas men had a two-fold increase in risk. ${ }^{67}$ Therefore, one cannot ignore the pronounced effects of sex hormones which regulate the body's metabolism, vasculature, and inflammation.

\section{Education}

Education affects the ability to make lifestyle decisions and/or self-manage a disease such as diabetes. ${ }^{68}$ Individuals with lower education levels have been shown to have higher rates of sedentary lifestyle, obesity, and alcohol consumption, all of which are recognized risk factors for the development or worsening of diabetes. ${ }^{67}$ Similarly, populations with lower literacy levels have been linked to a lower likelihood of using general preventive measures, which may lead to higher morbidity and mortality rates. ${ }^{69}$ Conversely, well-educated groups have been shown to be more capable of navigating or following complicated self-care regimens as used in the treatment of conditions such as HIV/AIDS and DM, thereby resulting in better health outcomes. ${ }^{70}$ Other studies have also found that education is linked to faster adoption of new medical technologies. ${ }^{71}$ One such study showed that in patients with DM the level of general education was significantly associated with referral. ${ }^{72}$ The authors concluded that their better-educated patients with DM were better advocates for their own health, and more likely to be referred earlier in the course of their condition. Therefore, differences in education contribute to health disparities.

\section{Marital Status}

Data have shown that there are health-augmenting outcomes associated with positive personal relationships, especially with marriage. ${ }^{73}$ In comparison with unmarried people, marriage offers a continued, long-lasting supportive environment which may promote physical and mental health. ${ }^{74}$ Higher rates of cardiovascular disease and premature mortality have been shown in individuals who have never been married vs those who have had their marriage ended through either death or divorce. ${ }^{75}$ One study found that after a 22-year follow-up, a significantly increased risk of T2DM was found among unmarried men. ${ }^{76}$ Interestingly, in an analysis of 379 men and women aged $\geq 70$ years, diabetes was found to be less prevalent among married vs unmarried, widowed or divorced individuals, ${ }^{77}$ and Martin et $\mathrm{al}^{78}$ found that there was a higher prevalence of DM among the widowed in comparison with married subjects. The theories which support the above include the "protective" aspect of marriage which is lost when the significant other has left or died, leading to loneliness, depression, risky health habits, poorer physical and cognitive function, poor self-rated health and increased risk of institutionalization. $^{73,79,80}$

\section{Employment Status}

The onset of T2DM usually occurs during the working life of individuals, with peak incidence in the fourth decade of life. ${ }^{81}$ Employment-related stressors such as shift work and work stress may trigger the development of T2DM through overactivation of the hypothalamic-pituitary-adrenal (HPA) axis and cortisol production. ${ }^{82-84}$ However, there is also evidence that individuals who lose their job are at greater risk of developing chronic diseases. ${ }^{85}$ The rate of cardiovascular mortality is doubled in those who are unemployed in comparison with employed people, particularly in the first year of unemployment. ${ }^{86,87}$ Unemployment may elevate lifestyle risk factors such as low nutrient diets, lack of exercise, increased smoking and alcohol abuse. ${ }^{88}$ Other inappropriate health behaviours could arise from changes in social relationships and psychological disorders which follow financial difficulties. ${ }^{89}$

\section{Economic Impact of Diabetes Mellitus}

In terms of the economic impact of DM, in the US Hogan et $\mathrm{al}^{90}$ documented that the medical expenditures associated with the disease in 2002 were estimated to be 132 billion US dollars. Ten 
years later (2012), the estimated costs were almost double (\$245 billion), of which $\$ 176$ billion was attributed to direct medical costs and $\$ 69$ billion for lost productivity costs. ${ }^{91}$ Complications and comorbidities associated with DM are responsible for the highest costs of diabetes management. For instance, Li et al ${ }^{92}$ demonstrated that females with a duration of $\mathrm{DM} \geq 15$ years, positive smoking history and several micro- and macrovascular complications attracted up to $50 \%$ more costs than those without the complications. In the same study, the most costly complication was end-stage renal disease treated with dialysis or transplantation, which was also approximately three to five times the cost of treating early-stage renal complications (microalbuminuria). ${ }^{91}$ Zhuo and colleagues estimated that $48-64 \%$ of the lifetime medical costs were attributable to DM-related complications, with $57 \%$ spent on macrovascular disease (stroke and coronary heart disease). ${ }^{93}$ In addition, men diagnosed with $\mathrm{T} 2 \mathrm{DM}$ when aged $\geq 65$ years spent approximately $64 \%$ of their costs on the treatment of diabetes-related complications, whilst those diagnosed between 25 and 44 years spent $\leq 50 \%{ }^{92}$ Diabetes is a cost burden to any economy, but in particular, LMICs which is where $80 \%$ of the world's DM population originate. ${ }^{1}$ In well-resourced high-income countries the economic burden lies with governments, whereas in LMICs, individuals with DM and their families often bear the brunt of high costs associated with insulin and other essential treatments. ${ }^{1}$ The impact of DM includes work disabilities, early retirement, loss of income/savings, lost work hours, absenteeism and presenteeism, most of which have negative effects on employment chances or work performance. ${ }^{94}$ A study by Travis Minor found that the employment probability of patients with T2DM is negatively impacted across both genders, and in addition, T2DM males are estimated to earn less than their healthier non-diabetic counterparts. ${ }^{95}$ Specifically, T2DM males have a "wage penalty" of about $52 \%$ after having lived with the disease for over 20 years. ${ }^{94}$ There is substantial expenditure associated with DM, its related complications as well as loss of productivity at work. Thus, it is necessary to pay closer attention to the control of risk factors and the disease itself through diabetes prevention and management programs, as well as to further prevent or reduce costly complications associated with the DM.

\section{Conclusion}

With the worldwide increase in high-calorie diets, sedentary lifestyles and urbanization, the prevalence of DM is rapidly mushrooming out of control. Yet, many individuals remain undiagnosed. Obesity has become established as one of the strongest risk factors for the development of DM and there appears to be a worrying trend that individuals with lower education levels and/or relative affluence are driving obesity rates rather than the reverse. There are multiple debilitating complications, some of which (eg retinopathy) are correlated with the duration, rather than the time of onset of DM. In addition to the classical risk factors, gender and ethnic differences make particular groups more susceptible to the onset of DM or DM-related complications. Education levels, urbanliving, employment and marital status contribute towards diabetes-related outcomes. There is substantial expenditure associated with DM, particularly diabetes-related complications. Lastly, the high prevalence of DM and its complications call for a multi-faceted strategy before the prospect of even further rises becomes a reality. Such a strategy could include the creation of public health awareness campaigns, improving current screening services, increasing diabetes educational efforts for healthcare professionals (HCPs) and non-HCPs (eg social workers) whilst further implementing diabetes specific treatment programmes and follow-up services, especially in under-serviced areas within developing countries.

\section{Funding}

This research did not receive any specific grant from any funding agency in the public, commercial or not-for-profit sector.

\section{Disclosure}

The authors declare that they have no competing/conflicts of interest pertaining to this work.

\section{References}

1. International Diabetes Federation. IDF Diabetes Atlas. 9th ed. Brussels, Belgium: International Diabetes Federation; 2019.

2. International Diabetes Federation. IDF Diabetes Atlas. Seventh Edition ed. Brussels, Belgium: International Diabetes Federation; 2015.

3. SEMDSA Guideline Committee. The 2017 SEMDSA guidelines for the management of type 2 diabetes. J Endocrinol Metab Diabetes $S$ Afr. 2017;22(1):S1-S196.

4. Newsholme EA, Dimitriadis G. Integration of biochemical and physiologic effects of insulin on glucose metabolism. Exp Clin Endocrinol Diabetes. 2001;109(Suppl 2):S122-S134. doi:10.1055/s-2001-18575

5. American Diabetes Association. Classification and diagnosis of diabetes. Diabetes Care. 2017;40(Suppl 1):S11-S24. doi:10.2337/dc17-S005

6. SEARCH for Diabetes in Youth Study Group. The burden of diabetes mellitus among US youth: prevalence estimates from the SEARCH for Diabetes in Youth Study. Pediatrics. 2006;118(4):1510-1518. doi:10.1542/peds.2006-0690

7. Levy-Marchal C, Patterson CC, Green A, Eurodiab ACE Study Group. Geographical variation of presentation at diagnosis of type I diabetes in children: the EURODIAB study. Diabetologia. 2001;44(3):B75B80. doi:10.1007/PL00002958 
8. Leslie RD, Williams R, Pozzilli P. Type 1 diabetes and latent autoimmune diabetes in adults: one end of the rainbow. J Clin Endocrinol Metab. 2006;91(5):1654-1659. doi:10.1210/jc.2005-1623

9. Stumvoll M, Goldstein BJ, van Haeften TW. Type 2 diabetes: principles of pathogenesis and therapy. Lancet. 2005;365 (9467):1333-1346. doi:10.1016/S0140-6736(05)61032-X

10. Romao I, Roth J. Genetic and environmental interactions in obesity and type 2 diabetes. $J$ Am Diet Assoc. 2008;108(4):S24-S28. doi:10.1016/j.jada.2008.01.022

11. Pierce M, Keen H, Bradley C. Risk of diabetes in offspring of parents with non-insulin-dependent diabetes. Diabet Med. 1995;12(1):6-13. doi:10.1111/dme.1995.12.issue-1

12. Vaag A, Brøns C, Gillberg L, et al. Genetic, nongenetic and epigenetic risk determinants in developmental programming of type 2 diabetes. Acta Obstet Gynecol Scand. 2014;93(11):1099-1108. doi:10.1111/aogs.2014.93.issue-11

13. Brix TH, Hansen PS, Kyvik KO, Hegedüs L. Cigarette smoking and risk of clinically overt thyroid disease: a population-based twin case-control study. Arch Intern Med. 2000;160(5):661-666. doi:10.1001/archinte.160.5.661

14. Vatanen T, Franzosa EA, Schwager R, et al. The human gut microbiome in early-onset type 1 diabetes from the TEDDY study. Nature. 2018;562(7728):589. doi:10.1038/s41586-018-0620-2

15. Farag YM, Gaballa MR. Diabesity: an overview of a rising epidemic. Nephrol Dial Transplant. 2011;26(1):28-35. doi:10.1093/ndt/gfq576

16. The Global Burden of Disease Obesity Collaborators 2015. Health effects of overweight and obesity in 195 countries over 25 years. N Engl J Med. 2017;377(1):13-27. doi:10.1056/NEJMoa1614362

17. Ogden CL, Carroll MD, Fryar CD, Flegal KM. Prevalence of obesity among adults and youth: United States, 2011-2014. NCHS Data Brief. 2015;219(1):1-8.

18. Wyatt SB, Winters KP, Dubbert PM. Overweight and obesity: prevalence, consequences, and causes of a growing public health problem. Am J Med Sci. 2006;331(4):166-174. doi:10.1097/ 00000441-200604000-00002

19. Serrano Rios M. Relationship between obesity and the increased risk of major complications in non-insulin-dependent diabetes mellitus. Eur $J$ Clin Invest. 1998;28:14-17. doi:10.1046/j.13652362.1998.0280s2014.x

20. Ginsberg HN, MacCallum PR. The obesity, metabolic syndrome, and type 2 diabetes mellitus pandemic: part I. Increased cardiovascular disease risk and the importance of atherogenic dyslipidemia in persons with the metabolic syndrome and type 2 diabetes mellitus. $J$ Cardiometab Syndr. 2009;4(2):113-119. doi:10.1111/j.15594572.2008.00044.x

21. Flegal KM, Ogden CL, Yanovski JA, et al. High adiposity and high body mass index-for-age in US children and adolescents overall and by race-ethnic group. Am J Clin Nutr. 2010;91(4):1020-1026. doi:10.3945/ajen.2009.28589

22. Hu Y, Bhupathiraju SN, De Koning L, Hu FB. Duration of obesity and overweight and risk of type 2 diabetes among US women. Obesity. 2014;22(10):2267-2273. doi:10.1002/oby.20851

23. Bastard JP, Maachi M, Lagathu C, et al. Recent advances in the relationship between obesity, inflammation, and insulin resistance. Eur Cytokine Netw. 2006;17(1):4-12.

24. Skinner AC, Skelton JA. Prevalence and trends in obesity and severe obesity among children in the United States, 1999-2012. JAMA Pediatr. 2014;168(6):561-566. doi:10.1001/jamapediatrics.2014.21

25. Kann L, Kinchen S, Shanklin SL, et al. Youth risk behavior surveillance-United States, 2013. MMWR Suppl. 2014;63(4):1-168.

26. Mozaffarian D, Hao T, Rimm EB, Willett WC, Hu FB. Changes in diet and lifestyle and long-term weight gain in women and men. $N$ Engl $J$ Med. 2011;364(25):2392-2404. doi:10.1056/NEJMoa1014296

27. Li C, Ford ES, Mokdad AH, Cook S. Recent trends in waist circumference and waist-height ratio among US children and adolescents. Pediatrics. 2006;118(5):e1390-e1398. doi:10.1542/peds.2006-1062
28. DeFronzo RA. From the triumvirate to the ominous octet: a new paradigm for the treatment of type 2 diabetes mellitus. Diabetes. 2009;58(4):773-795. doi:10.2337/db09-9028

29. Viner R, White B, Christie D. Type 2 diabetes in adolescents: a severe phenotype posing major clinical challenges and public health burden. Lancet. 2017;389(10085):2252-2260. doi:10.1016/S01406736(17)31371-5

30. Onge ES, Miller SA, Motycka C, DeBerry A. A review of the treatment of type 2 diabetes in children. $J$ Pediatr Pharmacol Ther. 2015;20(1):4-16. doi:10.5863/1551-6776-20.1.4

31. Shah AS, D'Alessio D, Ford-Adams ME, Desai AP, Inge TH. Bariatric surgery: a potential treatment for type 2 diabetes in youth. Diabetes Care. 2016;39(6):934-940. doi:10.2337/dc16-0067

32. Rubino F, Nathan DM, Eckel RH, et al. Metabolic surgery in the treatment algorithm for type 2 diabetes: a joint statement by international diabetes organizations. Diabetes Care. 2016;39(6):861-877. doi: $10.2337 / \mathrm{dc} 16-0236$

33. Beagley J, Guariguata L, Weil C, Motala AA. Global estimates of undiagnosed diabetes in adults. Diabetes Res Clin Pract. 2014;103 (2):150-160. doi:10.1016/j.diabres.2013.11.001

34. Motala AA, Esterhuizen T, Gouws E, Pirie FJ, Omar MA. Diabetes mellitus and other disorders of glycaemia in a rural South Africa community: prevalence and associated risk factors. Diabetes Care. 2008;31(9):1783-1788. doi:10.2337/dc08-0212

35. Plantinga LC, Crews DC, Coresh J, et al. Prevalence of chronic kidney disease in US adults with undiagnosed diabetes or prediabetes. Clin J Am Soc Nephrol. 2010;5(4):673-682. doi:10.2215/CJN.07891109

36. Hu YH, Pan XR, Liu PA, Li GW, Howard BV, Bennett PH. Coronary heart disease and diabetic retinopathy in newly diagnosed diabetes in Da Qing, China: the Da Qing IGT and Diabetes Study. Acta Diabetol. 1991;28(2):169-173. doi:10.1007/BF00579721

37. Wild SH, Smith FB, Lee AJ, Fowkes FG. Criteria for previously undiagnosed diabetes and risk of mortality: 15-year follow-up of the Edinburgh Artery Study cohort. Diabet Med. 2005;22(4):490-496. doi:10.1111/dme.2005.22.issue-4

38. Valdés S, Botas P, Delgado E, Cadórniga FD. Mortality risk in Spanish adults with diagnosed diabetes, undiagnosed diabetes, or prediabetes. The Asturias study 1998-2004. Rev Esp Cardiol 2009;62 (5):528-534.

39. Zoungas S, Woodward M, Li Q, et al. Impact of age, age at diagnosis and duration of diabetes on the risk of macrovascular and microvascular complications and death in type 2 diabetes. Diabetologia. 2014;57(12):2465-2474. doi:10.1007/s00125-014-3369-7

40. Krolewski AS, Warram JH, Rand LI, Kahn CR. Epidemiologic approach to the etiology of type I diabetes mellitus and its complications. $N$ Engl $J$ Med. 1987;317(22):1390-1398. doi:10.1056/NEJM198711263172206

41. Jerneld B, Algvere P. Relationship of duration and onset of diabetes to prevalence of diabetic retinopathy. Am J Ophthalmol. 1986;102 (4):431-437. doi:10.1016/0002-9394(86)90069-3

42. UK Prospective Diabetes Study (UKPDS) Group. Intensive blood-glucose control with sulphonylureas or insulin compared with conventional treatment and risk of complications in patients with type 2 diabetes (UKPDS 33). Lancet. 1998;352(9131):837-853. doi:10.1016/S0140-6736(98)07019-6

43. Mbanya JC, Sobngwi E. Diabetes microvascular and macrovascular disease in Africa. $J$ Cardiovasc Risk. 2003;10(2):97-102. doi:10.1177/174182670301000204

44. Sobngwi E, Mbanya JC, Moukouri EN, Ngu KB. Microalbuminuria and retinopathy in a diabetic population of Cameroon. Diabetes Res Clin Pract. 1999;44(3):191-196. doi:10.1016/S0168-8227(99)00052-2

45. Rahlenbeck SI, Gebre-yohannes A. Prevalence and epidemiology of micro- and macroalbuminuria in Ethiopian diabetic patients. J Diabetes Complications. 1997;11(6):343-349. doi:10.1016/S10568727(96)00122-5 
46. Kengne AP, Amoah AG, Mbanya JC. Cardiovascular complications of diabetes mellitus in sub-Saharan Africa. Circulation. 2005;112(23):3592-3601. doi:10.1161/CIRCULATIONAHA.105. 544312

47. Pérez-escamilla R, Putnik P. The role of acculturation in nutrition, lifestyle, and incidence of type 2 diabetes among Latinos. J Nutr. 2007;137(4):860-870. doi:10.1093/jn/137.4.860

48. Mckeigue PM, Shah B, Marmot MG. Relation of central obesity and insulin resistance with high diabetes prevalence and cardiovascular risk in South Asians. Lancet. 1991;337(8738):382-386. doi:10.1016/ 0140-6736(91)91164-P

49. Dhawan J, Bray CL. Angiographic comparison of coronary artery disease between Asians and Caucasians. Postgrad Med J. 1994;70 (827):625-630. doi:10.1136/pgmj.70.827.625

50. Dhawan J, Bray CL. Are Asian coronary arteries smaller than Caucasian? A study on angiographic coronary artery size estimation during life. Int J Cardiol. 1995;49(3):267-269. doi:10.1016/01675273(95)02315-N

51. Signorello LB, Schlundt DG, Cohen SS, et al. Comparing diabetes prevalence between African Americans and whites of similar socioeconomic status. Am J Public Health. 2007;97(12):2260-2267. doi:10.2105/AJPH.2006.094482

52. Karter AJ, Schillinger D, Adams AS, et al. Elevated rates of diabetes in Pacific Islanders and Asian subgroups: the Diabetes Study of Northern California (DISTANCE). Diabetes Care. 2013;36 (3):574-579. doi:10.2337/dc12-0722

53. Mcneely MJ. Outcomes of diabetes mellitus in Asian Americans. Nat Rev Endocrinol. 2011;7(7):378-379. doi:10.1038/nrendo.2011.91

54. Cooper-Patrick L, Gallo JJ, Gonzales JJ, et al. Race, gender, and partnership in the patient-physician relationship. JAMA. 1999;282 (6):583-589. doi:10.1001/jama.282.6.583

55. Caspersen CJ, Thomas GD, Boseman LA, Beckles GL, Albright AL. Aging, diabetes, and the public health system in the United States. Am J Public Health. 2012;102(8):1482-1497. doi:10.2105/ AJPH.2011.300616

56. Kirkman MS, Briscoe VJ, Clark N, et al. Diabetes in older adults. Diabetes Care. 2012;35(12):2650-2664. doi:10.2337/dc12-1801

57. Ulrich P, Cerami A. Protein glycation, diabetes, and aging. Recent Prog Horm Res. 2001;56(1):1-21. doi:10.1210/rp.56.1.1

58. Aronson D. Cross-linking of glycated collagen in the pathogenesis of arterial and myocardial stiffening of aging and diabetes. $J$ Hypertens. 2003;21(1):3-12. doi:10.1097/00004872-200301000-00002

59. Gu K, Cowie CC, Harris MI. Mortality in adults with and without diabetes in a national cohort of the US population, 1971-1993. Diabetes Care. 1998;21(7):1138-1145. doi:10.2337/ diacare.21.7.1138

60. Narayan KM, Boyle JP, Geiss LS, Saaddine JB, Thompson TJ. Impact of recent increase in incidence on future diabetes burden: US, 2005-2050. Diabetes Care. 2006;29(9):2114-2116. doi: $10.2337 / \mathrm{dc} 06-1136$

61. Singh VP, Bali A, Singh N, Jaggi AS. Advanced glycation end products and diabetic complications. Korean J Physiol Pharmacol. 2014;18(1):1-4. doi:10.4196/kjpp.2014.18.1.1

62. Ober C, Loisel DA, Gilad Y. Sex-specific genetic architecture of human disease. Nat Rev Genet. 2008;9(12):911-922. doi:10.1038/ $\operatorname{nrg} 2415$

63. Ng M, Fleming T, Robinson M, et al. Global, regional, and national prevalence of overweight and obesity in children and adults during 1980-2013: a systematic analysis for the Global Burden of Disease Study 2013. Lancet. 2014;384(9945):766-781. doi:10.1016/S01406736(14)60460-8

64. Wannamethee SG, Papacosta O, Lawlor DA, et al. Do women exhibit greater differences in established and novel risk factors between diabetes and non-diabetes than men? The British Regional Heart Study and British Women's Heart Health Study. Diabetologia. 2012;55(1):80-87. doi:10.1007/s00125-011-2284-4
65. Medrikova D, Jilkova ZM, Bardova K, Janovska P, Rossmeisl M, Kopecky J. Sex differences during the course of diet-induced obesity in mice: adipose tissue expandability and glycemic control. Int J Obes (Lond). 2012;36(2):262-272. doi:10.1038/ijo.2011.87

66. Carr MC, Brunzell JD. Abdominal obesity and dyslipidemia in the metabolic syndrome: importance of type 2 diabetes and familial combined hyperlipidemia in coronary artery disease risk. J Clin Endocrinol Metab. 2004;89(6):2601-2607. doi:10.1210/jc.2004-0432

67. Peters SA, Huxley RR, Woodward M. Diabetes as risk factor for incident coronary heart disease in women compared with men: a systematic review and meta-analysis of 64 cohorts including 858,507 individuals and 28,203 coronary events. Diabetologia. 2014;57(8):1542-1551. doi:10.1007/s00125-014-3260-6

68. Hwang J, Shon C. Relationship between socioeconomic status and type 2 diabetes: results from Korea National Health and Nutrition Examination Survey (KNHANES) 2010-2012. BMJ Open. 2014;4 (8):e005710. doi:10.1136/bmjopen-2014-005710

69. Howard DH, Sentell T, Gazmararian JA. Impact of health literacy on socioeconomic and racial differences in health in an elderly population. J Gen Intern Med. 2006;21(8):857-861. doi:10.1111/ j.1525-1497.2006.00530.x

70. Goldman DP, Smith JP. Can patient self-management help explain the SES health gradient? Proc Natl Acad Sci USA. 2002;99 (16):10929-10934. doi:10.1073/pnas.162086599

71. Glied S, Lleras-Muney A. Technological innovation and inequality in health. Demography. 2008;45(3):741-761. doi:10.1353/dem.0.0017

72. Rabi DM, Edwards AL, Southern DA, et al. Association of socio-economic status with diabetes prevalence and utilization of diabetes care services. BMC Health Serv Res. 2006;6(1):124. doi: 10.1186/1472-6963-6-124

73. House JS, Landis KR, Umberson D. Social relationships and health. Science. 1988;241(4865):540-545. doi:10.1126/science.3399889

74. Umberson D. Gender, marital status and the social control of health behavior. Soc Sci Med. 1992;34(8):907-917. doi:10.1016/02779536(92)90259-S

75. Stroebe M, Schut H, Stroebe W. Health outcomes of bereavement. Lancet. 2007;370(9603):1960-1973. doi:10.1016/S0140-6736(07) 61816-9

76. Cornelis MC, Chiuve SE, Glymour MM, et al. Bachelors, divorcees, and widowers: does marriage protect men from type 2 diabetes? PLoS One. 2014;9(9):e106720. doi:10.1371/journal.pone.0106720

77. Hiltunen LA. Are there associations between socio-economic status and known diabetes in an elderly Finnish population? Cent Eur J Public Health. 2005;13(4):187-190.

78. Martin SA, Haren MT, Taylor AW, Middleton SM, Wittert GA. Chronic disease prevalence and associations in a cohort of Australian men: the Florey Adelaide Male Ageing Study (FAMAS). BMC Public Health. 2008;8(1):261. doi:10.1186/1471-2458-8-261

79. Espinosa J, Evans WN. Heightened mortality after the death of a spouse: marriage protection or marriage selection? J Health Econ. 2008;27(5):1326-1342. doi:10.1016/j.jhealeco.2008.04.001

80. Murray JE. Marital protection and marital selection: evidence from a historical-prospective sample of American men. Demography. 2000;37(4):511-521. doi:10.1353/dem.2000.0010

81. Koopman RJ, Mainous AG, Diaz VA, Geesey ME. Changes in age at diagnosis of type 2 diabetes mellitus in the United States, 1988 to 2000. Ann Fam Med. 2005;3(1):60-63. doi:10.1370/afm.214

82. McEwen BS. Protective and damaging effects of stress mediators. $N$ Engl J Med. 1998;338(3):171-179. doi:10.1056/NEJM199801153380307

83. Morikawa Y, Nakagawa H, Miura K, et al. Shift work and the risk of diabetes mellitus among Japanese male factory workers. Scand J Work Environ Health. 2005;31(3):179-183. doi:10.5271/sjweh.867

84. Heraclides A, Chandola T, Witte DR, Brunner EJ. Psychosocial stress at work doubles the risk of type 2 diabetes in middle-aged women: evidence from the Whitehall II study. Diabetes Care. 2009;32 (12):2230-2235. doi:10.2337/dc09-0132 
85. Catalano R, Dooley D. Health effects of economic instability: a test of economic stress hypothesis. J Health Soc Behav. 1983;24 (1):46-60. doi:10.2307/2136302

86. Zagozdzon P, Zaborski L, Ejsmont J. Survival and cause-specific mortality among unemployed individuals in Poland during economic transition. J Public Health. 2009;31(1):138-146. doi:10.1093/ pubmed/fdn061

87. Dupre ME, George LK, Liu G, Peterson ED. The cumulative effect of unemployment on risks for acute myocardial infarction. Arch Intern Med. 2012;172(22):1731-1737. doi:10.1001/2013 jamainternmed. 447

88. Montgomery SM, Cook DG, Bartley MJ, Wadswarth MEJ. Unemployment, cigarette smoking, alcohol consumption and body weight in young British men. Eur J Public Health. 1998;8(1):21-27. doi:10.1093/eurpub/8.1.21

89. Steptoe A, Marmot M. The role of psychobiological pathways in socio-economic inequalities in cardiovascular disease risk. Eur Heart J. 2002;23(1):13-25. doi:10.1053/euhj.2001.2611
90. Hogan P, Dall T, Nikolov P. Economic costs of diabetes in the US in 2002. Diabetes Care. 2003;26(3):917-932.

91. American Diabetes Association. Economic costs of diabetes in the US in 2012. Diabetes Care. 2013;36(4):1033-1046. doi:10.2337/ dc12-2625

92. Li R, Bilik D, Brown MB, et al. Medical costs associated with type 2 diabetes complications and comorbidities. Am J Manag Care. 2013;19(5):421-430.

93. Zhuo X, Zhang P, Hoerger TJ. Lifetime direct medical costs of treating type 2 diabetes and diabetic complications. Am J Prev Med. 2013;45(3):253-261. doi:10.1016/j.amepre.2013.04.017

94. Breton MC, Guénette L, Amiche MA, Kayibanda JF, Grégoire JP, Moisan J. Burden of diabetes on the ability to work: a systematic review. Diabetes Care. 2013;36(3):740-749. doi:10.2337/dc12-0354

95. Minor T. An investigation into the effect of type I and type II diabetes duration on employment and wages. Econ Hum Biol. 2013;11 (4):534-544. doi:10.1016/j.ehb.2013.04.004
International Journal of General Medicine

\section{Publish your work in this journal}

The International Journal of General Medicine is an international, peer-reviewed open-access journal that focuses on general and internal medicine, pathogenesis, epidemiology, diagnosis, monitoring and treatment protocols. The journal is characterized by the rapid reporting of reviews, original research and clinical studies across all disease areas. The manuscript management system is completely online and includes a very quick and fair peer-review system, which is all easy to use. Visit http://www.dovepress.com/ testimonials.php to read real quotes from published authors. 